MATEC Web of Conferences 53, 01061 (2016)

DOI: $10.1051 /$ matecconf/20165301061

(C) Owned by the authors, published by EDP Sciences, 2016

\title{
Review on Shape Memory Materials
}

\author{
Maurizio Mor ${ }^{1, a}$ \\ ${ }^{1}$ Polibrixia, R\&D Department, 25123 Brescia, Italy
}

\begin{abstract}
In this work, the author tries to trace a route of shape memory materials from their definition, in terms of experimental observation and physical model to the application, especially in mechanical actuators and in device adopting this type of actuators.
\end{abstract}

\section{Introduction}

An interesting introduction to shape memory effect and to different types of shape memory actuators can be find in [1].

According to the type of stimulus, SMAs fall in two categories, one is thermo-responsive, and the other is magneto-responsive (i.e., ferromagnetic SMA) [2].

As such, the former can only be activated thermally by heating, while the latter can also be activated by applying a static magnetic field (magneto-responsive) or an alternating magnetic field (inductive heating) to trigger the SME. In both types, the reversible martensitic transformation is the underlying driving mechanism.

Thermo-responsive SMA has matured much more from the real engineering application point of view but many commercial applications are far from being realized. Therefore, author will only focused on thermo-responsive SMAs in this paper. Thermo-responsive SMA has matured much more from the real engineering application point of view and many commercial applications have, so far, been realized. Therefore, author will only focus on thermo-responsive SMAs in this paper.

There are three major types of SMA systems at present, namely $\mathrm{Cu}$-based (mainly $\mathrm{CuAlNi}$ and $\mathrm{CuZnAl}$ ), NiTi-based, and Fe-based (e.g., FeMnSi, FeNiC and FeNiCoTi). The first two are more suitable for engineering applications, while the last one is traditionally seldom used. SMAs based on NiTi are also more reliable and can be highly biocompatible. NiTi-based SMAs are more reliable and can be highly biocompatible.

Although the term "shape memory polymer" can be controversial, it is common in literature and it is associated to polymeric materials that, under a thermal trigger, are able to recover a shape. There is a variety of these examples; they are usually characterized by low exerted mechanical work, low speed and low cost with respect to shape memory metals. An interesting work [3] show also the possibility of combination of different materials (polymeric and metallic) to realize a multifunctional smart material system.

\section{State of the art on materials}

\footnotetext{
${ }^{\text {a }}$ Corresponding author : maurizio.mor@polibrixia.it
} 
An interesting field of research is on the constitutive model of materials.

Zhu Y., Zhang Y., and Zhao D. [4] shows a micromechanical constitutive model for phase transformation of NiTi polycrystalline SMA. By the assumption of laminated microstructure and perfect interfacial relationship for NiTi single crystal transformation, microscopic strain for each phase can be transformed to overall strain of respective volume element, and expression of phase transformation driving force is derived, then control equation of phase transformation is constructed. Based on the single crystal model, the NiTi polycrystalline constitutive model is constructed by Taylor assumption.

Zhou B. and Yoon S.H. [5] developed a macroscopic constitutive model of shape memory alloy considering cyclic effects. The progressive decrease of phase transformation critical stresses with the increased cycle number in such materials is assumed to be a result from the progressive increase of phase transformation critical temperatures upon the cyclic effects. A cyclic evolution equation is supposed to describe the influences of cycle effects on the material properties of the SMA under cyclic loading. A phase transformation equation expressing the phase transformation behaviors of the SMA under cyclic loading is established based on the differential relationship between martensitic volume fraction and the free energy increment of phase transformation. A mechanical constitutive equation predicting the mechanical characteristics of the SMA under cyclic loading is developed on the basis of thermodynamics and continuum mechanics.

Song Z., Dai H.H., and Sun Q.P. [6] worked on the propagation stresses in phase transitions of an SMA wire with new analytical formulas based on an internal-variable model. Based on the constitutive model in the literature with the specific Helmholtz free energy and rate of mechanical dissipation, the three-dimensional model is formulated. Identifying the characteristic axial strain as the small parameter, they arrive at the asymptotic one-dimensional equation which involves the stress, the axial strain and the phase state variable. By considering the evolution law of the phase state variable, the stress-strain relations corresponding to austenite, martensite and phase transition (phase mixture) regions are obtained. Although they take the dissipation into consideration, they find that each of the pure loading and unloading processes is equivalent to the Ericksen's bar problem with three branches in the stress-strain curve. As a result, they successfully deduce the analytical formulas for the nucleation stresses and propagation stresses.

Fonseca M.A., et al. [7], in their work, described a new class of shape-memory materials (SMMs) for applications in active control and morphing structures. These SMM can be metallic alloys (SMAs), piezoelectric, and polymers such as polyurethanes (SMPUs). The latter detain higher recovery rates but better processability; however, the reaction time is longer when compared with the SMA. The addition of carbon nanotubes (CNTs) to SMPU seems to improve its overall properties with a great deal of potential in what concerns improved shape memory.

Revathi A., et al. [8] described the effect of strain on the thermomechanical behavior of epoxy based shape memory polymers. They studied the effect of deformation strain on the thermomechanical (TM) behavior of a commercially available bifunctional epoxy resin modified with $5 \%$ carboxylterminated butadiene acrylonitrile (CTBN). The results were compared with those for the unmodified epoxy SMP. The cyclic thermomechanical tests performed here prove that the CTBN-epoxy SMP has a better endurance than the unmodified epoxy SMP, as well as enhanced shape-recovery characteristics.

Aggogeri F., et al [9] used Phase Change Materials in Machine Tools (MTs) thermostabilization in an inverse way to maintain the shape over a temperature exchange. By considering the main issues related to the thermal stability, authors presented the application of novel multifunctional material to Machine Tools structures. A set of advanced materials are considered: aluminum foams, corrugatecore sandwich panels and polymeric concrete beds. The adopted solutions have been infiltrated by phase change materials (PCMs) in order to maintain the thermal stability of MTs when the environmental temperature is perturbed.

Wang H.L., et al. [10] studied the stochastic bifurcation and first-passage failure of shape memory alloy beam subjected to stochastic excitation. Based on the isostrain loading and unloading experimental data of SMA (shape memory alloy), the van der Pol cycle model was used to 
characterize the hysteretic nonlinearity of material. According to the theory of elastic and Galerkin's method, the vibration model was built for the beam excited by the Gaussian noise. The Hamilton function was taken to describe the one dimensional diffusion process by using stochastic average method for quasi-non-integrable-Hamiltonian systems. Using the largest Lyapunov exponent and the singular boundary theory simultaneously, both the local and global stability of the system were studied. The stochastic Hopf bifurcation was analyzed by observing the changes of stationary and joint probability densities. Finally, the Backward Kolmogorov equation for the reliability function and the first-passage time was established and the numerical results were given under designated boundary and initial conditions.

Interesting stochastic models were build up for different materials [11, 12] incorporating the stochastic characteristic in the parameters of the material, that are considered as imperfectly known. This error in the knowledge of such parameters is then transferred to the prediction of the stochastic behavior of the material.

These innovative materials [13] are complex to modelize and often FEM approach are used [14] non-linear consitutive laws must be considered. A main lack of these materials for mechanical power generation ist he low enrgy efficiency associated with the thermomechanical conversion, thus proper energy saving tecniques must be implemented to obtain further interesting results [15, 16]. Furthermore the finishing of the material can play a role in thermic exchange thus proper evaluations of surface treatments must be taken in consderation [17].

\section{State of the art on systems}

Shape memory materials are usually used to realize movements [18], where these movements can be, under some considerations, designed with the well-known approaches just used for different industrial devices [9, 19-23]. Due to their compactness, shape memory systems used in micro-devices, where the connection between elements can be properly realized with flexure hinges [24] or, more generally, with flexible elements [25-29].

Degeratu et al. [30] proposed a thermal study of a shape memory alloy (SMA) spring actuator designed to insure the motion of a barrier structure.

Borboni et al. [31-33] designed a modular SMA actuator. The actuator is able to perform linear movements, while the modularity allows force and/or stroke improvements.

Clausi et al. [34] realized a robust actuation of silicon MEMS using SMA wires integrated at wafer-level by nickel electroplating. The integration method provides both high bond strength and electrical connections in one processing step, and it allows mass production of microactuators having high work density. SEM observation showed an intimate interconnection between the SMA wires and the silicon substrate. The variation of the actuators' performance across the wafer was evaluated on three $4.5 \mathrm{~mm} \times 1.8 \mathrm{~mm}$ footprint devices, proving repeatable results. The actuators showed a mean hot state deflection of $536 \mu \mathrm{m}$ and a mean stroke of $354 \mu \mathrm{m}$ at low power consumption (less than 70 $\mathrm{mW}$ ). One actuator was tested for $\mathrm{m} 150 \times 10^{3}$ cycles, and it demonstrated a highly reliable long-term performance, showing neither material degradation, nor failure of the nickel anchors.

Borboni et al. [19] proposed a fiber shaped micro-actuator for robotic gripping. This prototype is based on a shape memory alloy (SMA) actuator, on a dedicated PI controller and on software to command a desired motion profile for the actuator. The proposed micropositioning system is characterized by a $4 \mathrm{~mm}$ stroke, a $1 \mu \mathrm{m}$ resolution and a $70 \mathrm{~g}$ nominal force and can be commanded directly by a personal computer and without a human retroaction. The closed loop positioning resolution $(1 \mu \mathrm{m})$ is obtained in spite of an inaccurate system behavior during its movement.

SMA actuators are used in different applications to realize complex machines.

Furst et al. [35] realized a bat-inspired flapping-flight platform using shape memory alloy muscles and joints.

Amici et al. [25, 36] designed a parallel compliant meso-manipulator for finger rehabilitation treatments. Tiboni et al proposed a pneumatic mini-valve [37]. Kheirikhah et al. [38] proposed a new 
biomimetic earthworm robot for endoscopy actuated by SMA wires. Taveggia et al studied a rehabilitation device realized with SMA components $[39,40]$.

\section{Conclusions}

The research on shape memory materials and their applications is gaining new important results. The most new results on constitutive models are especially devoted to implement non-linear complex behaviors and stochastic characteristics. New materials show the possibility of combination of different materials (polymeric and metallic) to realize a multifunctional smart material system. Different applications are present in the most recent literature especially in robotics, welfare applications and bio-mimetics.

\section{References}

[1] Z. Wang, X. Zu, and Y. Fu, International Journal of Smart and Nano Materials, 2, 101-119, // 2011

[2] N. Pellegrini, 651, 42-48, 2013

[3] P. Ghosh, A. Rao, and A. R. Srinivasa, 2012

[4] Y. Zhu, Y. Zhang, and D. Zhao, Jinshu Xuebao/Acta Metallurgica Sinica, 49, 123-128, // 2013

[5] B. Zhou and S. H. Yoon, Science China: Physics, Mechanics and Astronomy, 1-10, // 2013

[6] Z. Song, H. H. Dai, and Q. P. Sun, International Journal of Plasticity, 42, 101-119, // 2013

[7] M. A. Fonseca, B. Abreu, F. A. M. M. Gonçalves, A. G. M. Ferreira, R. A. S. Moreira, and M. S. A. Oliveira, Composite Structures, 99, 105-111, // 2013

[8] A. Revathi, S. Rao, K. V. Rao, M. M. Singh, M. S. Murugan, S. Srihari, et al., Journal of Polymer Research, 20, 1-10, // 2013

[9] F. Aggogeri, A. Borboni, A. Merlo, and N. Pellegrini, Advanced Materials Research, 590, 252-257, 2012

[10] H. L. Wang, S. L. Yao, G. Ge, and J. Xu, Zhendong yu Chongji/Journal of Vibration and Shock, 31, 24-28, // 2012

[11] A. Borboni, D. De Santis, and R. Faglia, Proceedings of 8th Biennial ASME Conference on Engineering Systems Design and Analysis, 2006

[12] A. Borboni and R. Faglia, Journal of Applied Mechanics, 80, 021003-021003, 2013

[13] B. Stamatovic, R. Upadhyay, and N. Vatin, Procedia Engineering, 2015, 660-667

[14] V.V Okrepilov, V.N. Krutikov, G.I. El'kin, Measurement Techniques, 57 (2),109-116 (2014)

[15] V.L. Kvint, V.V Okrepilov, Herald of the Russian Academy of Sciences, 84 (3), 188-200 (2014)

[16] V.V Okrepilov, V.L. Makarov, A.R. Bakhtizin, S.N Kuzmina, Economy of Region, 2, 301$313(2015)$

[17] V.V Okrepilov, M.V. Leonidovich, Asian Social Science, 11 (7), 312-325 (2015)

[18] H. Yaguchi, K. Kamata, and K. Sasaki, 2012, 630-634

[19] F. Aggogeri, A. Borboni, R. Faglia, A. Merlo, and S. De Cristofaro, Applied Mechanics and Materials, 336-338, 1170-1173, 2013

[20] A. Borboni, F. Aggogeri, N. Pellegrini, and R. Faglia, Advanced Materials Research, 590, 399-404, 2012

[21] A. Borboni, R. Bussola, R. Faglia, P. L. Magnani, and A. Menegolo, Journal of Mechanical Design, Transactions of the ASME, 130, 0823011-0823016, 2008

[22] F. Aggogeri, A. Borboni, and R. Faglia, Applied Mechanics and Materials, 373-375, 130133,2013

[23] A. Borboni and M. Lancini, Journal of Vibration and Acoustics, Transactions of the ASME, 137, 1-9, 2015 
[24] N. Lobontiu, M. Cullin, M. Ali, and J. Hoffman, Mechanics Based Design of Structures and Machines, 41, 202-221, // 2013

[25] C. Amici, A. Borboni, and R. Faglia, Advances in Mechanical Engineering, 2010, // 2010

[26] A. Borboni and D. De Santis, Meccanica, 49, 1327-1336, 2014

[27] A. Borboni, D. De Santis, and R. Faglia, ASME 2010 10th Biennial Conference on Engineering Systems Design and Analysis ESDA2010, 2, 99-106, 2010

[28] C. Amici, A. Borboni, P. L. Magnani, and D. Pomi, Proceedings of EUCOMES 2008 - The 2nd European Conference on Mechanism Science, 2008, 487-493, 2009

[29] C. Amici, A. Borboni, P. L. Magnani, and D. Pomi, Proceedings of EUCOMES 2008 - The 2nd European Conference on Mechanism Science, 2008, 479-485, 2009

[30] S. Degeratu, P. Rotaru, S. Rizescu, and N. G. Bîzdoacă, Journal of Thermal Analysis and Calorimetry, 111, 1255-1262, // 2013

[31] A. Borboni, F. Aggogeri, N. Pellegrini, and R. Faglia, Advanced Materials Research, 590, 405-410, 2012

[32] A. Borboni, R. Faglia, and M. Palpacelli, MESA 2014 - 10th IEEE/ASME International Conference on Mechatronic and Embedded Systems and Applications, 1, 1-7, 2014

[33] A. Borboni and R. Faglia, Procedia Engineering, 2014, 1378-1381

[34] D. Clausi, H. Gradin, S. Braun, J. Peirs, G. Stemme, D. Reynaerts, et al., Sensors and Actuators, A: Physical, 189, 108-116, // 2013

[35] S. J. Furst, G. Bunget, and S. Seelecke, Smart Materials and Structures, 22, // 2013

[36] C. Amici, A. Borboni, R. Faglia, D. Fausti, and P. L. Magnani, IEEE/RSJ International Conference on Intelligent Robots and Systems, 2008, 735-740

[37] M. Tiboni, A. Borboni, M. Mor, and D. Pomi, Proceedings of the Institution of Mechanical Engineers. Part I: Journal of Systems and Control Engineering, 225, 443-451, 2011

[38] M. M. Kheirikhah, A. Khodayari, and S. M. Nikpey, 2012, 148-151

[39] G. Taveggia, J. H. Villafañe, F. Vavassori, C. Lecchi, A. Borboni, and S. Negrini, Journal of Manipulative and Physiological Therapeutics, 37, 242-252, 2014

[40] A. Borboni, R. Faglia, and M. Mor, ASME 2014 12th Biennial Conference on Engineering Systems Design and Analysis ESDA 2014, 1, 1-10, 2014 